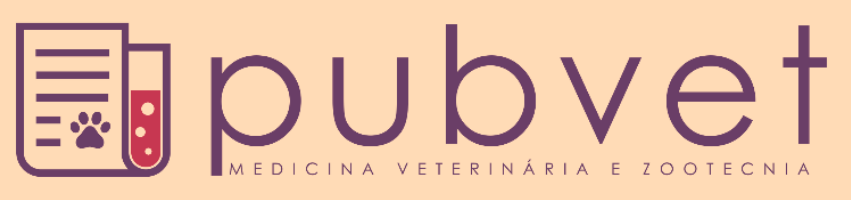

https://doi.org/10.31533/pubvet.v14n5a574.1-6

\title{
Uso da Enrofloxacina em surto de anaplasmose em bovinos leiteiros em Ijuí - RS: relato de caso
}

\author{
Bruna Carolina Ulsenheimer ${ }^{1^{*}} \bullet$, Dieison Elizandro Schvan ${ }^{2}$, Jorge Luis de Lima Shifer ${ }^{3}$, \\ Roberta Pereira Fontoura $^{40}$, Cristiane Elise Teichmann ${ }^{50}$ \\ IMestranda do Programa de Pós-Graduação em Medicina Veterinária, Universidade Federal de Santa Maria Santa Maria-RS, Brasil. \\ ${ }^{2}$ Engenheiro Agrônomo, Sociedade Educacional Três de Maio (SETREM), Três de Maio- RS, Brasil. \\ ${ }^{3}$ Médico Veterinário, Ijuí-RS, Brasil. \\ ${ }^{4}$ Professora Doutora do curso de Medicina Veterinária, Universidade Regional do Noroeste do Estado do Rio Grande do \\ Sul, Departamento de Estudos Agrários. Ijuí-RS, Brasil. \\ ${ }^{5}$ Professora Mestre do curso de Medicina Veterinária, Faculdade Santo Ângelo (FASA). Santo Ângelo-RS, Brasil. \\ * Autor para correspondência, E-mail: bru.brunna@hotmail.com
}

Resumo. Anaplasmose é uma enfermidade causada pela bactéria Anaplasma marginale, transmitida principalmente por carrapatos em rebanhos bovinos em todo o mundo, além da transmissão por insetos hematófagos e iatrogênica. Neste trabalho, objetivou-se descrever um surto de anaplasmose em seis bovinos leiteiros adultos na região de Ijuí-RS, apresentando sucesso na resolução clínica para os pacientes tratados com terapia antimicrobiana à base de enrofloxacina. De acordo com a anamnese, os animais que haviam morrido na propriedade, haviam apresentado sinais clínicos como: perda de apetite, mucosas ictéricas e no outro dia ocorria agravamento do quadro clínico, até a morte. O animal atendido em consulta veterinária, apresentou os mesmos sinais clínicos e ao exame clínico, observou-se, apatia, desidratação, palidez, mucosas ocular, oral, nasal e vulvar ictéricas, desidratação e quadro de hipersalivação. A queixa principal para a consulta era a relutância em alimentar-se, o emagrecimento e a diminuição da produção de leite, considerando-se que o animal já havia sido tratado para tristeza parasitária bovina há 2 dias, com diaceturato de diminazene e oxitetraciclina. Entretanto o diagnóstico foi confirmado pelo esfregaço sanguíneo e pelos achados de necropsia realizada em outro animal que veio a óbito na mesma propriedade, com mucosas e serosas ictéricas, com aumento excessivo no tamanho do fígado, baço e vesícula biliar, bem como a presença de sangue com aspecto aquoso e pelo esfregaço sanguíneo o qual resultou em presença de bactéria do gênero Anaplasma. Sendo instituído terapia antimicrobiana à base de enrofloxacina associada com fluidoterapia de ringer lactato, transfusão sanguínea, vitaminas e modificador orgânico, para o tratamento do paciente bovino. Devido a outros casos já relatados na região, acreditase existir algumas cepas da bactéria A. marginale, que apresentem resistência à oxitetraciclina, desta forma, a enrofloxacina surge como nova alternativa de tratamento para bovinos leiteiros com anaplasmose, refratários a utilização de oxitetraciclina.

Palavras chave: A. marginale, bactéria, icterícia, doença infecciosa, tristeza parasitária bovina

\section{Use of Enrofloxacin in an outbreak of anaplasmosis in dairy cattle in Ijui - RS: case report}

Abstract. Anaplasmosis is a disease caused by the bacterium Anaplasma marginale, transmitted mainly by ticks in cattle herds around the world, in addition to transmission by hematophagous and iatrogenic insects. In this work, the objective was to describe an outbreak of anaplasmosis in six adult dairy cattle in the region of Ijuí-RS, showing success 
in the clinical resolution for patients treated with enrofloxacin-based antimicrobial therapy. According to the anamnesis, the animals that had died on the property, had shown clinical signs such as: loss of appetite, jaundiced mucous membranes and on the other day the clinical condition worsened, until death. The animal seen in a veterinary consultation, showed the same clinical signs and the clinical examination, apathy, dehydration, pallor, jaundiced ocular, oral, nasal and vulvar mucous membranes, dehydration and hypersalivation. The main complaint for the consultation was the reluctance to eat, weight loss and decreased milk production, considering that the animal had already been treated for bovine parasitic sadness 2 days ago, with diminazene diaceturate and oxytetracycline. However, the diagnosis was confirmed by blood smear and the necropsy findings performed on another animal that died on the same property, with jaundiced mucous and serous, with an excessive increase in the size of the liver, spleen and gallbladder, as well as the presence of blood with an aqueous aspect and by the blood smear which resulted in the presence of bacteria of the genus Anaplasma. Antimicrobial therapy based on enrofloxacin associated with lactated ringer fluid therapy, blood transfusion, vitamins and organic modifier was instituted for the treatment of bovine patients. Due to other cases already reported in the region, it is believed that there are some strains of the bacteria Anaplasma marginale, which are resistant to oxytetracycline, thus, enrofloxacin appears as a new treatment alternative for dairy cattle with anaplasmosis, refractory to the use of oxytetracycline.

Keywords: A. marginale, bacteria, jaundice, infectious disease, bovine parasitic sadness

\section{Uso de enrofloxacina en un brote de anaplasmosis en ganado lechero en Ijuí-RS: informe del caso}

Resumen. La anaplasmosis es una enfermedad causada por la bacteria Anaplasma marginale, transmitida principalmente por garrapatas en rebaños de ganado de todo el mundo, además de la transmisión por insectos hematófagos e iatrogénicos. En este estudio, el objetivo fue describir un brote de anaplasmosis en seis vacas lecheras adultas en la región de Ijuí-RS, mostrando éxito en la resolución clínica para pacientes tratados con terapia antimicrobiana basada en enrofloxacina. Según la anamnesis, los animales que habían muerto en la propiedad habían mostrado signos clínicos tales como: pérdida de apetito, membranas mucosas con ictericia y el otro día la condición clínica empeoró, hasta la muerte. El animal tratado en una consulta veterinaria mostró los mismos signos y el examen clínicos, se observó apatía, deshidratación, palidez, ictericia ocular, membranas mucosas orales, nasales y vulvares, deshidratación e hipersalivación. La principal queja de la consulta fue la renuencia a comer, la pérdida de peso y la disminución de la producción de leche, teniendo en cuenta que el animal ya había sido tratado por tristeza parasitaria bovina hace 2 días, con diaceturato de diminazeno y oxitetraciclina. Sin embargo, el diagnóstico fue confirmado por el frotis de sangre y los hallazgos de la necropsia realizada en otro animal que murió en la misma propiedad, con ictericia mucosa y serosa, con un aumento excesivo del tamaño del hígado, el bazo y la vesícula biliar, así como la presencia de sangre con un aspecto acuoso y por el frotis de sangre que resultó en la presencia de bacterias Anaplasma similares. Se instituyó una terapia antimicrobiana basada en enrofloxacina asociada con la terapia con fluidos de ringer lactato, transfusión de sangre, vitaminas y modificadores orgánicos para el tratamiento de pacientes bovinos. Debido a otros casos ya reportados en la región, se cree que existen algunas cepas de la bacteria Anaplasma marginale, que son resistentes a la oxitetraciclina, por lo que la enrofloxacina aparece como una nueva alternativa de tratamiento para el ganado lechero con anaplasmosis, resistente al uso de oxitetraciclina.

Palabras clave: A. marginale, bacterias, icterícia, enfermedad infecciosa, tristeza parasitaria bovina 


\section{Introdução}

Dentre as doenças infecciosas, tem se destacado a anaplasmose, uma doença causada pela bactéria Anaplasma marginale, considerada o patógeno mais prevalente transmitido por carrapatos no mundo (Little, 2010; Silva \& Fonseca, 2013). Está distribuído nos seis continentes, responsável por alta morbidade e mortalidade em bovinos nas regiões temperadas, subtropicais e tropicais, incluindo o Brasil e outras regiões da América Latina (Quinn et al., 2005). Inclusive no Estado do Rio Grande do Sul, há elevados índices de perdas produtivas e morte de animais (Dalto et al., 2018).

Bactérias do gênero Anaplasma são patógenos intracelulares obrigatórios, pertencentes à ordem Rickettsiales (Radostits et al., 2010). A infecção de bovinos com A. marginale, causa a anaplasmose, devido á replicação do microrganismo nos eritrócitos. A transmissão ocorre biologicamente por carrapatos ou mecanicamente por insetos hematófagos, fômites ou sangue contaminado (Joazeiro, 2012; Quinn et al., 2005). Sendo o carrapato Rhipicephalus (Boophilus) microplus o principal responsável pela transmissão vetorial de A. marginale na América do Sul e Central (Silva \& Fonseca, 2013). A infecção causada por A. marginale, se caracteriza por estimular uma resposta imune, que acarreta na remoção de hemácias infectadas e não infectadas, podendo ocasionar diminuição do volume globular (Hostetler, 2017). Com período de incubação variando de duas a doze semanas (Quinn et al., 2005). Na fase aguda, cerca de 10 a $90 \%$ dos eritrócitos podem ser infectados, se caracterizando principalmente por anemia, devido a contínua hemólise (Radostits et al., 2010). A gravidade da infecção é baixa em animais com idade inferior a um ano e alta em bovinos com mais de 3 anos de idade (González \& Silva, 2008; Lopes et al., 2007; McGavin \& Zachay, 2013).

Neste trabalho, objetivou-se descrever um surto de anaplasmose em bovinos leiteiros adultos na região de Ijuí-RS, apresentando sucesso na resolução clínica para pacientes tratados com terapia antimicrobiana à base de enrofloxacina.

\section{Material e métodos}

Foi realizado atendimento clínico de uma fêmea bovina, da raça holandesa, com quatro anos de idade, pesando aproximadamente $550 \mathrm{~kg}$, com escore de condição corporal 2,75 (escala 1 - 5, onde 1 muito magro e 5 obeso), em uma propriedade no interior do município de Ijuí, Rio Grande do Sul, Brasil.

$\mathrm{Na}$ anamnese, o proprietário relatou que a vaca apresentava sinais clínicos semelhantes a outros seis animais que foram a óbito em sua propriedade, todos em um período de quatro meses. Segundo o proprietário, os animais iniciavam apresentando perda de apetite, mucosas ictéricas e no outro dia ocorria o agravamento do quadro clínico, até a morte. A queixa principal para a consulta do paciente, era a relutância em alimentar-se, o emagrecimento e a diminuição da produção de leite, considerandose que o animal já havia sido tratado para tristeza parasitária bovina há 2 dias, com diaceturato de diminazene e oxitetraciclina. A alimentação deste animal consistia basicamente em pastagem de aveia e azevém, silagem de milho, concentrado e água, permanecendo em piquete para pastoreio juntamente com outras vacas em lactação, porém havia alguns meses que os animais foram pastorear em área de grama tifton do seu vizinho, local com alta infestação de carrapatos.

Ao exame clínico geral, com o animal em estação, observou-se, apatia, $8 \%$ de desidratação, palidez, mucosas ocular, oral, nasal e vulvar ictéricas e quadro de hipersalivação. Com escore de fezes em 3, em uma escala de 1 a 5 (sendo que 1 é muito líquida e 5 é seca). Na auscultação foi possível verificar frequência cardíaca de $94 \mathrm{bpm}$, frequência respiratória de $26 \mathrm{mpm}$ e frequência ruminal de 1 movimento por minuto. A temperatura retal ao ser aferida estava em $38,9^{\circ} \mathrm{C}$, ao toque retal verificou-se que a vaca estava prenhe, com aproximadamente cinco meses de gestação. Foi realizada a coleta de sangue da veia caudal e encaminhado ao Laboratório de Patologia Clínica da Unijuí para pesquisa por hemoparasitas através de esfregaço sanguíneo.

No mesmo dia do atendimento à fêmea bovina, veio à óbito outro animal nesta mesma propriedade, com quadro clínico semelhante. Foi realizada a necropsia deste paciente. Para o exame, o animal foi posicionado em decúbito lateral, incidido na pele na região ventral do abdômen, fazendo a dissecação, após, uma incisão nos músculos abdominais (oblíquo externo do abdome, oblíquo interno do abdome, transverso do abdome e reto do abdome), abertura do peritônio e acesso a cavidade abdominal. Os órgãos presentes na cavidade abdominal foram exteriorizados, visualizando mucosas e serosas ictéricas, com 
aumento excessivo no tamanho do fígado, baço (Figura 1) e vesícula biliar (Figura 2), bem como a presença de sangue com aspecto aquoso.

Devido a anamnese, sinais clínicos, exame de esfregaço sanguíneo e necropsia de outro animal na mesma propriedade com os mesmos sinais clínicos, confirmou-se o diagnóstico de anaplasmose na fêmea bovina.

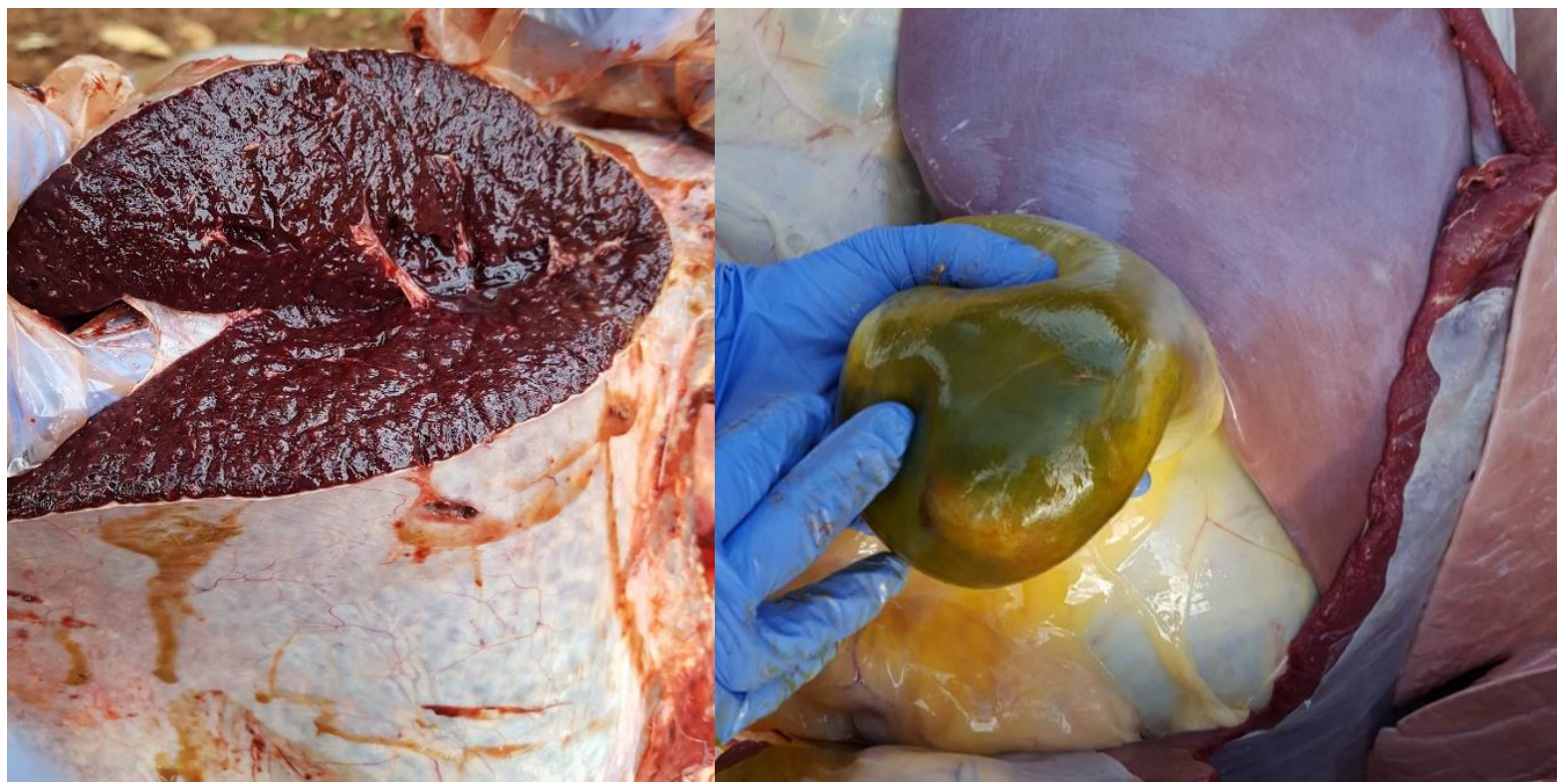

Figura 1. Esplenomegalia em necropsia de bovino Figura 2. Vesícula biliar distendida em necropsia de bovino acometido pela Anaplasma marginale acometido pela Anaplasma marginale

Desta forma, instituiu-se o tratamento para a anaplasmose, com transfusão de 2 litros de sangue, por via intravenosa (IV), 1 litro de fluidoterapia intravenosa (IV) com ringer lactato $(6 \mathrm{mg} / \mathrm{ml}$ de cloreto de sódio, solução fisiológica de Ringer com Lactato de Sódioß), sendo receitado aplicar após 24 h 1 litro novamente, $15 \mathrm{ml}$ de enrofloxacino por via intramuscular (IM) $(2,5 \mathrm{mg} / \mathrm{kg}$, Enro Flec $10 \%$ Injetável®) $1 \mathrm{X}$ ao dia por 3 dias, $15 \mathrm{ml}$ de vitaminas e modificador orgânico por via subcutânea (SC) $(2,5 \mathrm{mg} / \mathrm{ml}$ de vitamina B1, Decamin-B $\left.{ }^{\circledR}\right)$ e pasta bovina 34 g (3,0 x 10 UFC de Ruminobacter amylophilum, Floramax $\left.{ }^{\circledR}\right)$ via oral, $1 \mathrm{X}$ ao dia por 3 dias. Sendo recomendado ao paciente permanecer em repouso, dentro do galpão de alimentação, evitando movimentos bruscos e estenuantes. Por cinco dias após o tratamento, retornamos a propriedade e foi constatado a melhora clínica do paciente.

\section{Resultados e discussão}

Segundo Santos et al. (2017) a anaplasmose ocorre sob a forma de instabilidade enzoótica, podendo predispor a ocorrência de surtos. Com predomínio de infecção subclínica por A. marginale em bovinos na fase de cria e recria (Carvalho et al., 2012), podendo este ser um dos motivos em que não houve manifestação clínica em bovinos jovens na propriedade, apenas em vacas leiteiras adultas com idade superior a três anos de idade.

Dentre os achados clínicos considerados por Carlson (2006) na fase inicial da anaplasmose há o aumento na temperatura retal com febre de 39,5 a $41^{\circ} \mathrm{C}$, parâmetro que não estava alterado na paciente bovina nesta fase da doença, devido ao fato do atendimento clínico ser realizado 12 a 24 horas posterior ao início da doença, onde a temperatura pode se encontrar normal ou abaixo do fisiológico (Megid et al., 2016). Os sinais clínicos descritos por Radostits et al. (2010), incluem anemia, mucosas ictéricas, dispneia intensa e agressividade, com animais hiperexcitáveis antes do óbito. $\mathrm{O}$ animal do caso relatado não apresentou sinais de agressividade, nem dispneia, provavelmente por ainda não estar num estágio tão avançado da doença. Já Carlson (2006) aponta anorexia, queda na produção leiteira, supressão da ruminação, ressecamento do focinho e letargia como os principais sinais clínicos a serem observados em animais com anaplasmose, porém no caso relatado neste estudo, o paciente não apresentou supressão da ruminação nem ressecamento do focinho, cogita-se esta possibilidade devido ao paciente ser atendido 
de 12 a 24 horas após o início dos sinais clínicos. Porém vacas gestantes com anaplasmose, geralmente abortam (Radostits et al., 2010), devido a febre que o paciente apresenta e a anoxia fetal (Megid et al., 2016), fato que ocorreu no paciente atendido, entre o quinto e sétimo dia após o início da doença.

O diagnóstico foi confirmado pelo exame complementar de esfregaço sanguíneo, pesquisa por hemoparasitas, o qual resultou em presença de bactéria do gênero anaplasma. Sendo que ao examinar a amostra sanguínea em microscópio óptico, este agente é identificado na periferia dos eritrócitos (Radostits et al., 2010). Contudo, a confirmação do diagnóstico também poderia ser realizada por PCR, ELISA e fixação de complemento (Quinn et al., 2005).

Os achados de necropsia da fêmea bovina que foi a óbito, corroboram com os descritos por Fighera \& Graça (2017), na qual também evidenciaram lesões que caracterizam tipicamente uma doença hemolítica extravascular. Assim como, Zachary et al. (2012) que encontraram além dos tecidos ictéricos, pode-se observar a esplenomegalia, conforme figura 1, hepatomegalia, vesícula biliar distendida (Figura 2) e esplenomegalia conforme já descrito por Radostitis et al. (2010).

Para o tratamento da anaplasmose a terapia antimicrobiana com fármacos da família da Tetraciclinas é o principal protocolo terapêutico recomendado (Alberton et al., 2015). Carlson (2006) indica a utilização de antimicrobianos a base de tetraciclinas, como a oxitetraciclina. Entretanto, a oxitetraciclina foi utilizada na tentativa de tratamento para o rebanho da propriedade, e esta não demonstrou eficiência na ação antimicrobiana, pois os animais continuavam morrendo. Desta forma, instituiu-se o tratamento à base de enrofloxacina, antibiótico bactericida, da família das quinolonas, de amplo espectro que age inibindo a síntese de DNA e RNA bacteriano (Papich, 2012). Em estudo realizado por Alberton et al. (2015), com o intuito de testar a eficiência antimicrobiana do dipropionato de imidocarb, cloridrato de oxitetraciclina e enrofloxacina, observou que os três protocolos terapêuticos foram capazes de reduzir a infecção ao longo do tratamento, porém, após cinco dias de tratamento, a enrofloxacina apresentou maior efetividade para o tratamento em relação aos demais.

A terapia instituída foi considerada de sucesso, salvando a vida deste animal. Onde a utilização de vitaminas do complexo B, como a B1 foi importante para ocorrer a transformação de carboidratos em lipídios, excitação de nervos periféricos e na síntese de adenosina trifosfato (ATP) e a B6 contribuiu para a manutenção de resposta imune adaptativa (Paulino \& Rizzo, 2014). Já a utilização de fluidoterapia com ringer lactato foi administrada no paciente com o intuito de reposição de fluidos para correção da desidratação e reposição eletrolítica, pois a mesma possui em sua composição sódio, potássio, cloreto e cálcio (Papich, 2012).

Após o tratamento do animal o prognóstico foi favorável; porém, Zachary et al. (2012) afirmam que os pacientes sobreviventes a infecção, tornam-se portadores crônicos e desta forma, reservatórios da doença para outros animais. Segundo Santos et al. (2017) o uso indiscriminado de carrapaticida, a presença de carrapatos, a idade, a raça e o município de residência dos animais podem ser considerados fatores de risco para ocorrência da doença. Portanto para o controle da anaplasmose em áreas endêmicas, é indicado a utilização de banhos acaricidas com base no resultado do biocarrapaticidograma (Radostits et al., 2002), sendo indicado esta estratégia para todo rebanho da propriedade.

\section{Conclusão}

Foi possível confirmar o surto de anaplasmose em bovinos leiteiros na região de Ijuí-RS por meio dos achados de necropsia e pelo esfregaço sanguíneo. Neste estudo, constatou-se que já existem cepas da bactéria anaplasma marginale encontrada na região, com resistência à oxitetraciclina, devido a resposta satisfatória e efetiva com antibioticoterapia à base de enrofloxacina. São necessários mais exames complementares através da biologia molecular para diagnosticar com maior precisão à quais fármacos as cepas de Anaplasma marginale apresentam resistência.

\section{Referências bibliográficas}

Alberton, L. R., Orlandini, C. F., Zampieri, T. M., Nakamura, A. Y., Gonçalves, D. D., Piau Júnior, R., Zaniolo, M. M., Cardim, S. T., Vidotto, O. \& Garcia, J. L. (2015). Eficácia do dipropionato de imidocarb, da enrofloxacina e do cloridrato de oxitetraciclina no tratamento de bovinos naturalmente 
infectados por Anaplasma marginale. Arquivo Brasileiro de Medicina Veterinária e Zootecnia, 67(4), 1056-1062.

Carlson, G. P. (2006). Doenças dos sistemas hematopoiético e hemolinfático. In B. P. Smith (Ed.), Medicina interna de grandes animais (pp. 1049-1050). Manole Ltda.

Carvalho, A. H. O., Silva Júnior, F. A., Daher, D. O., Rocha, C. M. B. M. \& Guimarães, A. M. (2012). Efeito do sistema de produção de leite sobre a estabilidade enzoótica para Anaplasma marginale e Babesia bovis em bezerras na região do Campo das Vertentes de Minas Gerais, Brasil. Semina: Ciências Agrárias, 33(1), 323-332.

Dalto, A. G. C., Reck Junior, J., Martins, J. R., Bitencourt, A. P. G., Feltrin, C. \& Driemeier, D. (2018). Controle de anaplasmose bovina através de imunização com Anaplasma centrale. Pesquisa Veterinária Brasileira, 38(6), 1064-1067.

Fighera, R. A. \& Graça, D. L. Sistema hematopoiético. In: SANTOS, R. L. \& ALESSI, A. C. Patologia Veterinária. 2. ed. Rio de Janeiro: Roca, 2017, Cap. 6, p. 395.

González, F. H. D. \& Silva, S. C. (2008). Patologia clínica veterinária: texto introdutório. Universidade Federal do Rio Grande do Sul.

Hostetler, D. E. (2017). Sistema circulatório e tecidos linfoides. In D. S. McVey, M. Kennedy, \& M. M. Chengappa (Eds.), Microbiologia Veterinária (p. 551 p.). Guanabara Koogan.

Joazeiro, A. C. P. (2012). Detecção e diferenciação de Anaplasma marginalee Anaplasma centralepor reação em cadeia de polimerase (PCR). Universidade Federal do Rio Grande do Sul.

Little, S. E. (2010). Ehrlichiosis and anaplasmosis in dogs and cats. Veterinary Clinics: Small Animal Practice, 40(6), 1121-1140.

Lopes, S. T. A., Biondo, A. W. \& Santos, A. P. (2007). Manual de patologia clínica veterinária (Vol. 1). Universidade Federal de Santa Maria.

McGavin, D. \& Zachay, J. F. (2013). Bases da patologia em veterinária. Elsevier Brasil.

Megid, J., Ribeiro, M. G. \& Paes, A. C. (2016). Doenças infecciosas em animais de produção e de companhia. Roca.

Papich, M. G. (2012). Manual Saunders de Terapia Veterinária. Elsevier Health Sciences Brazil.

Paulino, C. A. \& Rizzo, M. S. (2014). Vitaminas. In H. S. Spinosa, J. Palermo-Neto, \& S. L. Górniak (Eds.), Medicamentos em animais de produção (pp. 151-153). Spinosa, H.S.

Quinn, P. J., Markey, B. K., Carter, M. E., Donnelly, W. J. \& Leonard, F. C. (2005). Microbiologia veterinária e doenças infecciosas. Artmed.

Radostits, O. M., Gay, C. C., Blood, D. C., Hinchcliff, K. W. \& McKenzie, R. A. (2010). Clínica Veterinária: um tratado de doenças dos bovinos, ovinos, suínos, caprinos e eqüinos (Vol. 1). Guanabara Koogan.

Santos, G. B., Gomes, I. M. M., Silveira, J. A. G., Pires, L., Azevedo, S. S., Antonelli, A. C., Ribeiro, M. F. B. \& Horta, M. C. (2017). Tristeza Parasitária em bovinos do semiárido pernambucano. Pesquisa Veterinária Brasileira, 37(1), 1-7.

Silva, J. B. \& Fonseca, A. H. (2013). Analysis of the risk factors related to the immune humoral antiAnaplasma marginale in dairy cattle. Semina: Ciencias Agrarias, 34(2), 777-784.

Zachary, J. F., McGavin, D. \& McGavin, M. D. (2012). Bases da patologia em veterinária. Elsevier Brasil.

Recebido: 26 de fevereiro, 2020.

Aprovado: 28 de março, 2020.

Disponível online: 18 junho, 2020.

Licenciamento: Este artigo é publicado na modalidade Acesso Aberto sob a licença Creative Commons Atribuição 4.0 (CC-BY 4.0), a qual permite uso irrestrito, distribuição, reprodução em qualquer meio, desde que o autor e a fonte sejam devidamente creditados. 